\title{
Questions of uncertainty in geography
}

\author{
Giovanni Fusco, Matteo Caglioni, Karine Emsellem, Myriam Merad, \\ Diego Moreno and Christine Voiron-Canicio
}

Université Côte d'Azur, CNRS, ESPACE, France

\begin{abstract}
The concept of uncertainty has fostered in the last decade's fundamental and applied research in different disciplinary fields. Couclelis (2003) clearly demonstrated the pervasiveness of uncertainty in the production process of geographical knowledge. The paper shares this epistemological point of view. Pragmatically, its goal is to show how questions of uncertainty arise in the praxis of geographic research. It suggests that scientific work can be enriched, and not hindered, by addressing uncertainty in knowledge. The paper discusses eight domains within the activity of the geographer, where questions of uncertainty arise: geographic information, geographic definitions, the explanation of geographic phenomena, the complexity of spatial systems, geosimulation, the representation of spatial knowledge, subjectivity in spatial phenomena, and planning. Within each domain uncertainty issues are identified as well as their possible interrelations.
\end{abstract}

\section{Keywords}

Uncertainty, geographic knowledge, geographic concepts, geographic information, planning, complexity, geosimulation, visualization, subjective space

\section{Introduction: a growing awareness of uncertainty}

The concept of uncertainty was first introduced in economics (Knight, 1921) to extend the traditional view of error theory and risk assessment. In the last 30 years, it has fostered fundamental and applied research in different disciplinary fields. More particularly, applied mathematics and computer science have developed formal theories of uncertain knowledge (Dubois and Prade, 1988; Gaines, 1978; Halpern, 2005; Shafer, 1976; Zadeh, 1978) in artificial intelligence. More recently, natural and social sciences, like archeology (De Runz, 2008), biology (Hey et al., 2003; Zbilut and Giuliani, 2008) and, of course, economics and management (Walker et al., 2003, 2013) have formulated practical questions of uncertain knowledge, which correspond only partially to these theoretical 
frameworks. Interdisciplinary research is also arising on issues of uncertain knowledge (Fusco et al., 2015).

In geography, like in other disciplines, the concept of uncertainty is an umbrella term (Longley et al., 2011) covering different aspects on non-certain knowledge in geographical space: incomplete knowledge, inaccurate knowledge, imprecise knowledge, fuzzy knowledge, disputed knowledge, ambiguous knowledge, impossible knowledge, etc. Questions of uncertain knowledge were perceived earlier in the domain of geographical information (Duckham et al., 2001). The formalization needed in geographical information systems confronted geographers and GIS scientists with the "weaknesses" of real geographical data. But in the GIS domain, knowledge was also considered through the narrow prism of data-related issues.

At the same time, a growing awareness of the conceptual and theoretical implications of uncertain knowledge arose in the discipline, beyond technical considerations in the GIS domain. In this respect, interest in uncertain knowledge can be put in parallel with the postmodern turn in many social sciences (Best and Kellner, 1997). Within the traditional positivist paradigm, scientific knowledge was certain knowledge. Uncertainty was thus a negative term, whose limits had to be pushed further by scientific research. This view is still shared common sense in our discipline. Nevertheless, uncertainty is now recognized by a growing number of geographers (Burrough and Frank, 1996; Couclelis, 2003; Fisher, 2000; Plewe, 2002; Rolland-May, 1984) as an essential component of geographic knowledge. Previously "hidden under the carpet", uncertainty becomes thus an issue that cannot be avoided in geographic research, both theoretical and applied.

Couclelis (2003) clearly demonstrated the pervasiveness of uncertainty in the production process of geographical knowledge from GIS data. Uncertainty is not only a question of poor, imprecise, inaccurate, incomplete data, which could be overcome (at least in theory) with new, better data. Much more fundamentally, uncertainty arises whenever knowledge is produced from data through human reasoning. The authors of this paper share this epistemological point of view.

Fourteen years after Couclelis' founding paper, we want to widen the discussion to other uncertainties in geographic knowledge, not necessarily related to treatments of GIS data. Our main goal is to show how questions of uncertainty do arise in the praxis of geographic research. More precisely, we want to suggest how scientific work can be enriched, and not hindered, by addressing uncertainty in knowledge. We thus identified eight domains within the activity of the geographer, where questions of uncertainty arise. Within this exploratory analysis, we want to understand which questions are more crucial in each domain, and how they interrelate.

\section{Uncertainty in geographic information}

Uncertainty was firstly tackled in GIS studies, and this domain remains the one where questions of uncertainty are most widely conceptualized and solutions are proposed (Duckham, 2002; Duckham et al., 2001; Fisher et al., 2006; Foody and Atkinson, 2002; Prade et al., 2010; Zhang and Goodchild, 2002). The aforementioned works focus on the treatment of uncertainty in spatial data, which is a prerequisite for further spatial analysis. Uncertainty appears in the incoherences between the modelling primitives of GIS and real spatial information, in data granularity, in spatio-temporal aggregation and disaggregation of data, in incomplete and/or conflicting data sources, etc. (Foody and Atkinson, 2002; Caloz, 2005; Olteanu-Raimond et al., 2009). Sometimes data are already affected by error functions, when they are derived from measurement or sampling procedures. Global data 
quality has thus to be stored in metadata or uncertainty levels referred to specific geographic objects can be integrated as semantic information. Heuvelink (2002) shows the complexity of propagating uncertainty in GIS. Even when probabilities are given to quantify data uncertainty, standard Monte Carlo simulations are normally not enough to propagate uncertainties correctly. Huge conditional probabilities matrices should be stored with GIS data and correct geostatistical estimation methods should be applied before performing Monte Carlo simulations. However, GIS users will rarely be willing to use such time-consuming procedures. Simpler, approximate and less time-consuming procedures are needed. Following Vazirgiannis et al. (2003), He et al. (2004) propose to use uncertainty-based protocols of knowledge discovery from spatial databases. Bayesian probabilities, fuzzy logics and evidence theory are proposed as possible frameworks to integrate uncertainty in spatial data mining. Comber et al. (2007) apply these protocols to landscape element recognition, showing how scale and grain are paramount in problem definition.

Several authors have also proposed taxonomies of uncertainty in geographic information (Fisher, 2005; Fisher et al., 2006; Shu et al., 2003). As these works show, one of the most crucial issues of uncertainty in geographic information is to be able to distinguish the precise nature and origin of uncertainty and to use the most appropriate formalisms to model them with a GIS.

Some classical spatial analysis techniques directly deal with questions of uncertainty, even if in strict terms of probabilistic modelling. Kriging is thus based on a probabilistic approach to data interpolation, point pattern analysis techniques also implement statistic tests based on Poisson random process, etc. Several contributions in Foody and Atkinson (2002) address the issue of the uncertainties introduced (or removed) in the geostatistical treatments. As already pointed out by Heuvelink (2002, 2007), the issue here is to integrate uncertain inputs and propagate their uncertainties in the geoprocessing.

New emerging issues can also be mentioned, as the questions of uncertainty in volunteered geographic information (VGI) (Flanagin and Metzger, 2008; Ostermann and Spinsanti, 2011) and in big-data (Bendler et al., 2014). Volunteered information, for example, increases the quantity and variety of data available for analysis on GIS: images, street networks, land-uses, opinions are now constantly being edited from citizens on the Internet. In the absence of an "authoritative" source evaluating the quality and the protocols of these data, uncertainty questions become even more central. As we will see in section Uncertainty in planning and risk management, Roche et al. (2013) show how uncertainties in VGI, and more in general in GeoWeb, play a role in reducing complete ignorance, while at the same time introducing new uncertainties, in the context of crisis management.

The importance of the research field of uncertainty in GIS is witnessed by the success of at least two major research networks, both linked to a biennial conference: the International Spatial Accuracy Research Association and the International Symposium on Spatial Data Quality. Nevertheless, however rich this research field is, it does not cover all questions of uncertainty in geographic knowledge. It seems to us that it has even focused the attention of geographers and shadowed other fundamental uncertainty questions, which will be addressed in the following sections.

\section{Uncertainty in geographic definitions}

Uncertainty in the definition of geographic objects is widely discussed among geographers, but is rarely formalized and integrated in geographic analysis. Major issues in geographical analysis are related to uncertainty in ambiguous, heterogeneous or differently applicable definitions of objects and concepts: city, region, continent, frontier, system, etc. Some of 
these objects can have non-ambiguous and crisp definitions through social conventions (as the limits of most administrative units, when they are not disputed), but many more suffer fundamental uncertainties in their theoretical, as well as practical, definitions. Coombes et al. (1979), for example, highlight the difficulties and the ambiguities inherent in a theoretical and practical definition of urban regions, even when "objective" data like commuter flows are used to identify functional regions. These uncertainties are the consequence of the unavoidable gap between geographic reality and the logical categories used in geographic analysis semantics (Ban and Ahlqvist, 2009; Bennett, 2001; Burrough and Frank, 1996; Fisher, 2000; Plewe, 2002). They can have an impact on the previously mentioned uncertainty in geographic information, much more than measurement errors or missing data. Following the evolution of urban population in a country is thus not just a problem of reliable census data over time, but much more of consistent and appropriate definitions of "city" and "inhabitant". The theoretical and practical impossibility of forcing the continuum of reality in crisp logical categories, suggests the use of fuzzy set theory, fuzzy logic (Burrough and Frank, 1996; De Ruffray, 2007; Fisher, 2000; Plewe, 2002; Rolland-May, 1984) and rough set theory (Murgante et al., 2007) to describe geographical space. When uncertainties derive from ambiguous or conflicting definitions, belief functions can offer interesting solutions. It is thus to be regretted that Dempster-Shafer evidence theory is essentially used to fuse conflicting geographic data (Malpica et al., 2007) and that no application has been attempted to conflicting object definitions given by geographers or formal geographic ontologies. Comber et al. (2007), for example, use evidence theory to classify landscape elements by taking into account conflicting elements of evidence, but they do not address the case of conflicting conceptual definitions of landscape classes.

Uncertainties in the definition of geographic objects should clearly be of utmost importance for uncertainties in GIS data. This is, unfortunately, seldom the case. Uncertainties in attributing an urban and a rural census population to a municipality is thus not just a problem of census data accuracy but much more fundamentally a problem of geographic definition. In France, the National Statistics Institute defines as urban all municipalities as having more than 2000 inhabitants, in China, this threshold is orders of magnitude higher and is inextricable from administrative criteria (Chung and Lam, 2010), in India, functional criteria like the percentage of non-agricultural workers is also considered, and so on. Which uncertainties arise from the use of these thresholds? How could GIS data take into consideration both data inaccuracy and data sensitivity to definitions of geographic objects? Formal ontologies have traditionally been seen as a way to reduce uncertainty in geographic object definitions. Projects like Citygml (Kolbe, 2005) have thus been developed to eliminate uncertainties deriving from incoherences in object definition by different urban practitioners. It is nevertheless questionable whether crisp ontologies can always find a consensus in the scientific community for modelling such complex and fuzzy objects like cities, informal settlements, local ecosystems, functional regions, cultural areas, etc. Within the artificial intelligence community, Bobilo and Straccia (2011), Costa et al. (2008), Ding and Peng (2004) and Loiseau et al. (2006) propose uncertainty-based ontologies for dealing with uncertain object definitions. Fuzzy logics, Bayesian probabilities and possibility theories are the proposed methods to enrich traditional formal ontologies. Laskey et al.(2010) have thus proposed applications of uncertainty-based ontologies for geospatial information. Caglioni and Fusco (2014) proposed to extend the use of uncertainty-based ontologies to models of relations between geographic phenomena. Uncertainty-based formal ontologies should be challenged in the future to tackle the description of complex geographic phenomena like spatial processes resulting from systems of relations among geographic 
objects evolving in time and space (urbanization, globalization, gentrification, geomorphogenetic processes, climate change, etc.).

\section{Uncertainty in the explanation of geographic phenomena}

Uncertainty can also characterize the kind of explanatory knowledge geographers can produce. In his foreword to Foody and Atkinson (2002), Curran (2002) draws a distinction between measurement uncertainty and understanding uncertainty. The former relates to the accuracy of spatial data and has drawn much attention from the GIS community. The latter qualifies the confidence we have in our explanations of phenomena; contrary to public opinion expectations, scientific knowledge is always affected by uncertainty: "Scientific knowledge is a body of statements of varying degrees of certainty - some most unsure, some nearly sure, but none absolutely certain" (Feynman, 1988: 245). Two main issues are particularly relevant for geographers here.

The first concerns the way geographers can identify explanations of geographical phenomena, abstracting from data. The traditional view in theoretical and quantitative geography, well presented by Harvey (1969), can use a probabilistic approach to test theoretical explanations using empirical data. The underlying hypothesis is nevertheless the possibility of identifying the "good" explanation for observed data, with negligible uncertainty. Contrary to this view, Quine (1980[1953]) argues that empirical data under-determine any theoretical lawful explanation (several theories can explain the same data). Von Bertalanffy (1968) shows that this is normally the case for phenomena within open systems and uses the concept of equifinality. Varenne (2015) develops Quine's and Von Bertalanffy's argument to theoretical and quantitative geography, remarking the existence of a double underdetermination: empirical data under-determine statistical laws (Law/Data underdetermination, as several statistical laws can conveniently fit the data); but statistical laws under-determine geographic processes (Process/Law under-determination, as several theoretical processes can produce the same statistical distributions). This double underdetermination results in irreducible uncertainties in the kind of explanatory knowledge geographers can produce. What geographers need are thus methods to identify and eventually quantify these uncertainties, and to integrate them in geographic reasoning in a context of multiplicity of possible explanations, as for example in Fusco and Tettamanzi (2017).

The second issue concerns the capability of geographical explanations to be generalized. In the first place, geographical "laws" are regularities obtained through comparative analysis, whether qualitatively (case-study analysis) or quantitatively (identification of statistical regularities, see above). As they are not deterministic natural laws, they suffer exceptions and are specific to a given spatio-temporal context. This is even more true for human geography. In this respect, what uncertainties arise when a general knowledge is used to explain a given case study? What uncertainties characterize, on the other hand, the generalization of the explanation found for a given geographic space to another? The first question relates to the fact that geographical "laws" are summaries of system properties (general causation), whereas explaining a given case study is a question of specific causation. This is a distinction which is well known in forensic studies (Federal Judicial Center, 2011) and passing between the two categories of causation is known to arise questions of uncertainty. The second question needs a clarification. Geographers rarely apply "laws" blindly to new case studies, when these "laws" were determined for a different context. When this is done, the "law" is considered as a hypothesis to be verified, and its applicability to the new case studies is by definition uncertain. What is peculiar to the 
production of knowledge in the social sciences is precisely the interest and the need to always test "laws" with new data. The validity of an explanatory knowledge is never absolute, and researchers need to accumulate evidence for its soundness and/ or limits to its validity by confronting it to new case studies. In this context, being aware of the levels of uncertainty of present theoretical explanations is a way to improve the heuristics of geographical research.

Of course, uncertainties attached to the explanation of geographical phenomena are also linked to uncertainties in data and in object definitions. Uncertain explanation of the link between land-use and transportation in a city is thus at the same time a problem of multiple causation, of poor data quality and of approximate or arbitrary definition of land-uses and mobility system elements.

\section{Uncertainty and the complexity of spatial systems}

Complexity is a new paradigm which has renewed scientific research in several disciplinary fields. The underlying hypothesis of complexity is that many research objects are complex systems characterized by a multitude of elements and relations among elements. Their overall behaviour cannot be deduced directly from the characteristics of the single elements (holistic approach), as the classical reductionist approach of Descartes proposed, because new system properties emerge from the interactions of its components. Complex systems are also characterised by nested levels of organisation, which can reproduce the whole system at different scales (holographic behaviour). Another important characteristic of complex systems is, paradoxically, their capacity to deal with high levels of micro-disorder (entropy) and mesoand macro-order (negentropy) through self-organising processes. According to Morin (1990, 1994), these characteristics are peculiar of most social and biological systems. Weaver (1948) indeed recognised two forms of complexity: disorganized and organized complexity, the former characterizing many physical systems, the latter corresponding to Morin's definition of complex socio-biological systems.

The knowledge we can have of complex systems is by definition uncertain. The extreme numerosity of parameters precludes the researcher from having any complete set of measurements of the objects under investigation. Even more crucially, the impossibility of reductionist approaches to complex systems, would make any set of "complete" measurements of individual components inadequate to the understanding of the organic whole. According to Weaver (1948), probabilistic models can still give adequate descriptions of disorganized complexity. On the contrary, knowledge of organized complexity often resists descriptions in terms of simple probabilistic models. Higher levels of uncertainty arise, linked to the impossibility of exhaustive descriptions both of individual components/relations and of overall behaviours, which are often emerging properties of the many interactions within the system. Within an open complex system (and all real-world geographic systems are open), the already mentioned equifinality problem also poses the question of the knowability of the processes producing observed phenomena.

Manson (2001) and Dauphine' (2003) propose general theories of complexity for geographical systems. More specifically, complex system approaches have been proposed and used in urban geography (Allen, 1997; Batty, 2013; Portugali, 2000). In an interesting review of Dauphine' 's work, Di Me' o (2005) points out that, as in other human and social sciences, the high numerosity of elements and relations (aggregate complexity) is not the only source of complexity in geography. Hermeneutics of subjects within a social context (see section Uncertainty and subjectivity in spatial phenomena) also contribute to complexity in geographic systems. 
This debate goes clearly beyond the scope of our paper and points to the complementarity of knowledge on complex systems produced by different research approaches in our discipline. In this respect, uncertainties (which are hard to quantify) could be attributed to results obtained by any sub-disciplinary approach in a context of concurrent (and sometimes divergent) theoretical bodies of knowledge.

We want to stress the necessity to explore the implications of the complex system approach on the kind of knowledge we can produce on geographic phenomena. Unpredictability has, for example, been identified already in deterministic complexity: simple deterministic systems can exhibit chaotic behaviour with system state being particularly sensitive to initial conditions. Lorentz (1969) applied these considerations very early to meteorological phenomena. O'Sullivan (2004) has promptly observed that other characteristics of complex systems (namely the convergence to organization which is typical of organized complexity) create a tension with the apparent randomness and unpredictability of certain geographic phenomena. In his view, this apparent contradiction between convergence and divergence can be solved when we consider the geographical scale of analysis. Divergence and unpredictability of phenomena at the micro-scale could thus be compatible with convergence to some structural properties at the macro-scale. These properties could nevertheless only be appreciated qualitatively. Uncertain, approximate, "soft" knowledge seems the only possible knowledge of complex systems in many practical situations (Capra, 1997). An issue often underestimated by geographers using complex system approaches is thus the importance of formalizing their research results in terms of uncertain knowledge. More operational considerations will be addressed when models of complex systems are used for geographic space (see next section).

\section{Uncertainty in geosimulation}

Since Tobler's (1979) proposal for a Cellular Geography, geosimulation has proved its utility in depicting geographic phenomena. Geosimulation offers a set of techniques going beyond statistical and differential equation models. Much more, it offers the new perspective of simulating spatial phenomena as the emerging results of collective dynamics of interacting objects, an approach well suited to model complex spatial systems (Benenson and Torrens, 2004). Complexity of simulated phenomena leads to non-deterministic models, beyond Von Neumann's original cellular automaton. These models are not predictable by definition and the consequence of this is the ignorance of analytical solutions. Before performing a simulation of a non-deterministic model, we cannot know the behaviour of the model. The value of parameters and variables will be calculated locally with numerical methods, the overall behaviour of the system emerges from these local calculations.

Uncertainty in spatial modelling and simulation is an important issue in theoretical and quantitative geography. Modelling is one way to describe and understand geographic space, but it requires a simplification of observed complex phenomena. Choices in entitization and variable selection imply uncertainties in geographic information and definition of geographic objects, as previously discussed (see sections Uncertainty in geographic information and Uncertainty in geographic definitions). Modelling also deals with uncertainty in describing relationships between entities (rules, equations, spatial and temporal relations). Hypotheses underlying those relationships are uncertain and imply causality links, which are not always provided by empirical studies (see section Uncertainty in the explanation of geographic phenomena).

Entities and their relationships constitute the model structure. Another common simplification is considering the invariance of this structure over time, above all in human 
geography. Stationarity of processes and of model structure is a strong hypothesis that leads to a divergence between model and reality, and it adds uncertainty in our simulation of reality. Nowadays we can consider non-stationary models thanks to advanced methods like adaptive algorithms and the evolutionary design of models (Ribeiro et al., 2005); nevertheless, uncertainty is omnipresent in simulation results.

Geosimulation models provide a virtual laboratory for geographers and even a second empirical reality (Daude' , 2005). This virtual geographic space introduces further levels of uncertainty in the knowledge produced during all the modelling chain: from the chosen hypotheses of formal representation of real-world phenomena to model conceptualisation, from input data to output data, from rules and equations to the results of simulation, from the parameter and variables choice to their calibration using uncertain data, from representation and visualisation to evaluation and validation of results.

A major issue in geosimulation is thus to develop methods to quantify uncertainty, like sensitivity analysis, expert assessment, model comparison or statistical approaches (Uusitalo et al., 2015). Error theory explains how variance is propagated through several calculation sequences, but simulation results can show different shades of uncertainty, depending not only on data errors. Even though we are computationally able to model a dynamic process in some detail, infinite spatial simulations can be produced based on different parametrizations and specifications of the model. Not all model outputs are equally plausible, and several scenarios are more probable/possible than others. Moreover, the validity of model results for the understanding of real-world phenomena is neither assured by the internal coherence of the model nor verifiable with external data, given the equifinality problem (O'Sullivan, 2004). Modelling complex hydrological systems, Beven and Freer (2000) have addressed equifinality through the generalized likelihood uncertainty estimation (GLUE) methodology. This is a multiple model identification procedure allowing for equifinality and integrating the possibility of multiple model specifications producing a set of uncertain results. Models explored by the GLUE methodology must nevertheless belong to a given family of models, a constraint which is probably acceptable in hydrological problems, but not necessarily in the more varied geosimulation models of socioeconomic interactions in space. More in general, and without addressing specifically complex geosimulation models, Walker et al. (2013) identify several levels of uncertainty in the modelling process, from complete certainty to total ignorance. In presence of shallow uncertainty, it is still possible to calibrate a given model (considered as "certain" in its correspondence to reality) and obtain a statistical distribution of errors. At deeper uncertainty levels we are no longer able to describe the system in statistical terms; several models of the same reality are possible. More than simple sensitivity analysis, an exploration of model results under different parameterizations (behaviour space analysis) and specifications (model comparison) is needed. Evaluation of result robustness and validity through a mix of expert assessment and statistical procedures is the most usual way of addressing uncertainty. In this context, GLUE represents an interesting alternative for a probabilistic evaluation of uncertainty through model "fusion". Specific computational problems arise when models have the complex architecture of geosimulation models. Here new perspectives are opened by platforms of intensive calculus and distributed computing, like OpenMole (Reuillon et al., 2015). Thus, Pumain and Reuillon (2017) show using the OpenMole platform how to tackle uncertainties related to equifinality issues in geosimulation: a multi-modelling framework is used to model urban growth in soviet and post-soviet cities by including several concurring explanatory mechanisms. Exploration of 
parameter space can identify the most plausible combinations of mechanisms which consistently produce the observed data.

Nevertheless, at even deeper levels of uncertainty, we could have several (often incomplete) models based on conflicting and incompatible theoretical assumptions, with incomparable structures, allowing different narratives of system behaviour and possible outcomes. At this level of uncertainty, a harmonized quantification of the uncertainties of model results seems unattainable.

When geosimulations are used in decision support contexts (see section Uncertainty in planning and risk management), the uncertainty-burdened results clearly suggest that model outcomes should be only used to explore possible scenarios (equally plausible or of graduated plausibility) and not as forecasts of future state of a spatial system.

\section{Uncertainty in representing spatial knowledge}

The representation and visualization of geographic knowledge have traditionally found in maps a well suited vector of communication. Ancient maps were already confronted with questions of uncertain knowledge ("Terra incognita" writings are found on maps and pilot books until the early XVIII century). The on-going investigation of the globe surface, the advances in geodesy and topography and the availability of new spatial data allowed the production of modern cartography and choropleth thematic maps. Given the scale of representation and the object selection associated with this scale, modern cartography favours the impression of a geographic reality perfectly known. Graphic semiology of map representations is particularly conceived for "well known" geographic objects and phenomena.

In his "Atlas of Ignorance", Boggs (1949) was the first to point out the practical and theoretical impossibility of this paradigm of complete, certain knowledge in maps. As a popular quotation among cartographers goes, generally attributed to Bert Friesen, once a map is drawn people tend to accept it as a reality. In the last decades, postmodern criticism of cartography has thus highlighted the fallacies of maps (Harley, 1988; Monmonier, 1993), in particular when they play on the impression of objective, complete, certain knowledge communicated to their users.

Representing uncertain knowledge in maps is thus a double challenge: we need in the first place to find appropriate protocols of representation and communication of uncertain geographic knowledge; in the second place, we also have to overcome the tacit assumption of certain knowledge conveyed by modern maps and thematic maps.

On the first point, research was carried out since the 1990s on new cartographic solutions for representing uncertain geographic data (Arnaud and Davoine, 2009; Buttenfield and Weibel, 1988; Cedilnik and Reinghans, 2000; Fisher, 1994; MacEachren, 1992; MacEachren and Taylor, 1994; Pang et al., 1997; Rocchini et al., 2011). Representing data on a map is not all: sometimes more synthetic geographic knowledge can benefit from representation in the form of a sketch which can eventually be formalized as a chorematic diagram (Brunet, 1980). Unfortunately, chorematic diagrams were never conceived to represent uncertain geographic knowledge. More recent research projects, aiming at automated production of synthetic chorematic diagrams from spatial data (Del Fatto, 2009; Laurini and Servigne, 2011) miss the point of introducing questions of uncertain knowledge.

On the contrary, sketches and chorematic diagrams have an unexploited potential for representing uncertain knowledge. First, they aim at representing general structures of 
geographic knowledge and not choropleth data; they are thus more qualitative in nature and can better represent uncertain, imprecise geographical objects and phenomena. Furthermore, they integrate time better than maps. Both Couclelis (2010) and Brunet (1980) underline that a sketch and a chorematic diagram are to be read in time: it is not the final representation that matters but the step-by-step procedure to enrich the sketch/diagram and to arrive to the final representation. Time can thus be used to overlay conflicting knowledge over which the geographer is not certain. The role of uncertainty in schematic representations has been further studied from a cognitive point of view. Scrivener et al. (2000), for example, analyse the link between uncertainty, memory recall and cognitive process in designer's sketches. Their work could open further research on mental maps of geographic space, but is also relevant when schematic representations are produced by analysts as a synthesis of their expert knowledge: uncertainty should be better recognised as a main driver in the geographer's cognitive process and sketching can help in this endeavour.

Introducing time in knowledge representation and using digital platforms have thus become key ingredients of some of the latest solutions for the representation of uncertain geographic knowledge: interactive geographic data visualization. First attempts of interactive representation of uncertain geographic data were proposed in the 1990s (Ehlschlaeger et al., 1997 ) even if they were not considered particularly effective in their applications (Evans, 1997). Advances of the software interfaces have since been considerable and new applications seem to be both more user-friendly and scientifically sophisticated (Ban and Ahlqvist, 2009; Cao and Fusco, 2015; Dubois et al., 2017; Kunz et al., 2011). These applications link together interactive representations in the forms of maps, diagrams and text. Interactive representation of more synthetic geographic knowledge through sketches and chorematic diagrams is still a research perspective.

Uncertainty-related issues of representation are directly linked to the use of uncertain geographic knowledge in decision support, as in planning or in risk management (see section Uncertainty in planning and risk management). Several authors thus relate of the evaluation of different solutions for representing uncertain geographic knowledge in a decision support or in a communication process (Aerts et al., 2003; Edwards and Nelson, 2001; Evans, 1997; Harrower, 2007). The Netherlands Environmental Assessment Agency has thus produced a guidance for uncertainty assessment and communication (Visser et al., 2006) to help the reporting, representation and communication of uncertain spatial data on environmental issues.

\section{Uncertainty and subjectivity in spatial phenomena}

Geography also deals with the perceived space (Cosgrove, 1998; Di Mé o, 1991; Tuan, 1977) which goes beyond what could be considered as material and objective space described in the previous points. Some authors (see for example Lake, 1993 and Smith, 1979 ) tend at that point to oppose "objectivity" that is accurate and "subjectivity" that is considered as ill-framed, uncertain and volatile. This perceived experience of space is based on identity, feelings, social constructs, values, ideologies, etc. in short on all "rational" and "irrational" elements that drive the behaviour of individuals and social groups in space. Indeed, subjective space is the one of the individuals in their singularities and their specificities, but is also perceived and constructed collectively through the establishment of meta- spatial structures. 
Publications and research on this field tend to be divided into three major categories. A first category of research, that we called "descriptive", explores the diversity of factors that can explain how perception of space is framed and how, these "perceived issues" that are a way to deal with the unknown and the uncertain can be explicit for an actor or a group of actors. This is the case for the works done for example by Fini et al. (2015) and by Weichhart (2013) that we present hereafter.

Indeed, Fini et al. (2015) point out the fact that the way space is apprehended is subjective. The perception of what is considered as "near" and as "far" is dependent on our motion capabilities. The authors also show that the needs of humans to reduce their uncertainties associated to an agent (or an interface) and to increase the level of confidence on it are achieved through an anthropomorphism process.

Since the future is uncertain, Weichhart (2013) suggested an innovative approach to learning based on Bertalanffy's General System Theory mixing Chaos and Complex Adaptive Systems theories. In this paper, the author supports Dewey's criticisms on traditional educational approaches and suggests to frame new learning environments, such as GIS for example, that are more adapted to face the uncertain and the unknown. These tools can be used to enable the education of self-controlled active agents capable of creative problemsolving.

A second category of research, that we call "prescriptive", suggests new methods to deal with the different issues of the individual, the group and the aggregate perception for decision support or for problem structuring. The researches produced by McCarty et al. (2014) and Thill and Sui (1993) are an illustration of this category. McCarty et al. (2014) propose a model to explain why there is an increasing polarized US Congress with an apparently stable and centrist US electorate. Based on previous works, they suggest to follow the literature on the distribution of preference across voters rather than considering the average behaviour. Indeed, the median voter was found to be an inadequate predictor of candidate or legislative positions. Based on the geography of preferences, they suggested a model of uncertainty over the median legislator that could help to solve the Fiorina puzzle. ${ }^{1}$

Preferences are a construct. Considering this point, there is a variability in people liking and disliking places. Based on the early work done by Gould, on preferences for geographic space and residential desirability, Thill and Sui (1993) have empirically tested and demonstrated that the dominant viewpoint in a group is not affected by the fuzziness in individual space preferences. They show that mental maps based on Gould's ranking methodology can reveal a distorted representation of residential preferences. Their study confirms that interval scales are more adapted than ordinal scales for mental mapping and more largely for behavioural analysis.

And it is here that the scientific question of uncertainty appears. Indeed, the emergence of higher-level spatial structures implies generalizing individual subjective space. But how to combine the different subjectivities in space? As any spatial characteristic of the subjective space refers to personal features, singular, not standardized, and inevitably rich and varied, how can we have a collective vision without uncertainty? So when two spatial perceptions differ (even slightly), which values can be attributed with certainty to a place? Similarly, as field geographers, how can we address the subjectivity of interview data and their related uncertainties? Moreover, given the abundance of self-produced data by citizens (VGI on nuisances, on the different perceptions, etc.), how to deal with data which are rich and new, but overexposed to the uncertainties (of location, knowledge of the subject and the object, the very existence of the object, etc.). In short, the dimension of the perceptual "subject" undeniably raises the question of uncertainty. 
A third category of research, that we call "problem setting", questions the way uncertainty and perception are considered and investigated until now. The concepts of "validity" and "accuracy" are than evoked. Some can consider that the theme of uncertainty seems to be not sufficiently explicated in social and cultural readings of space. They argue that in the large majority of scientific work addressing subjective space, uncertainty is not clearly mentioned, sometimes forgotten or poorly discussed. The research addresses more the richness and the diversity of individual subjectivity, and aims at highlighting the effects of spatial (distance, situation, etc.) or social structures (transmission, kinship, cultural filters, etc.) on the perception. These researches hardly question the variability, the relativity, the blurring or the accuracy of these individual and collective spatial behaviours. Individual cases accumulate in space but the validity and significance of the constructed spatial meta-structure seem not formally addressed. One of the critics can be illustrated, for example, by looking at gender studies (Di Mé o, 2012) that reveal the territories, the networks and the places of women in town; they show the influence of political and urban structures. But subjectively perceived spaces and lived spaces are not discussed in their similarity and their ability to be generalized. This subjectivity is discussed primarily on its legitimacy where the state of knowledge of the subject matters more than its validity, and hence introduces a degree of inherent uncertainty for the researchers.

However, some studies deal with the uncertainty dimension of subjective space data. Lynch (1960) and Rowntree (1997), for example, have raised the issue of the difficult passage from individual mental maps of urban space to collective mental maps for a given social group. Unfortunately, they did not explore and formalize the questions of uncertainty associated to this passage. Didelon et al. (2011) have addressed uncertain knowledge of a territorial object (Europe) and cartographic solutions to represent it. Their simple question "draw me Europe" asked to almost 10,000 students implies several types of uncertainty (imprecision, vagueness, graduation, ambiguity, etc.) on various elements: the territorial object, cartographic knowledge, personal experience of European space, knowledge of geography of Europe, etc. The use of fuzzy set theory allows them to define degrees of belonging to Europe. Other authors have more particularly assessed the uncertainties associated to VGI (Flanagin and Metzger 2008; Ostermann and Spinsanti, 2011, see section Uncertainty in geographic information).

Considering these three categories of research in the field of uncertainty on subjective knowledge of space as a main contribution could eventually become a bridge between quantitative geography and social and cultural geography.

\section{Uncertainty in planning and risk management}

Within the last two decades, uncertainty has become a growing issue in planning. Questions of sustainable development and environmental concerns favoured the awareness that the future is undetermined and possible trajectories of development for local territories are uncertain. The way to consider uncertainty differentiates spatial strategic foresight from planning. Planning was traditionally based on forecast analyses where the future was considered as a continuation of past trends and structural factors were considered invariant. Spatial strategic foresight differs from forecast analysis because it considers it impossible to "forecast" the future (Cuhls, 2003). Loinger and Spohr (2005) consider spatial strategic foresight (prospective territoriale in French) as an effort of organization in the presence of uncertainty, and even, to a certain degree, of "planning" the uncertain.

Nevertheless, other authors like Chalas and Soubeyran (2010), show that uncertainty was never absent neither in the theory nor in the praxis of planning; on the contrary, it was 
linked, in different forms, to planning. First, uncertainty is what the planner tries to eliminate by programming an action in a place. Secondly, uncertainty is linked to the unintentional consequences of planning actions. Planners tackle it by trying to estimate future risks, by carrying out impact assessments or simulations for the possible futures of the planned operation. A last uncertainty puts in question planning as conscious and deliberate intervention on geographic space. Indeed, the meaning of the operation will only emerge a posteriori and cannot be as deliberate as planning theory goes. Examples of unintentional consequences of planning actions, with negative consequences on the environment or on the local community, put then in question the meaning of the planned actions and of the very decision making process. In front of this kind of uncertainty, planners are at a loss.

In her PhD thesis, Pellegrino (2010) deals with uncertainty in urban planning. Uncertainty is considered as inherent in society. She identifies a "positive uncertainty" in the praxis of urban projects, where planning goes beyond the action of professional planners and where new strategies are set up to deal with unforeseeable processes. These strategies rely on new participative, multi-source, flexible, fuzzy tools within a multi-scale approach.

Today, uncertainty is intruding into local project management in different ways. First, by involving public consultations in the project definition, monitoring and assessment. Second, by including more flexibility in the operation under development. Since the early 1990s, mediating participatory modelling has been used to enable local communities to improve their adaptability to the uncertainty of their environment; to find the practice that is best adapted to the uncertain climate, by using role-playing games and agent-based models, for instance (D'Acquino and Bah, 2013a). This new approach can be described as "surfing on uncertainty (Berkes and Folke, 1998) rather than contending with it" (D'Acquino and Bah, 2013b). Third, the awareness of the unpredictability of the future challenged traditional planning strategies and tools and favoured a new planning approach: reversibility. The concept of reversibility and its operationalization are currently encouraged in urban planning (Scherrer and Vanier, 2013). Blecic and Cecchini (2016) go even further by applying Taleb's antifragility concept to planning. Antifragility is the property of complex systems that can improve themselves through perturbations of their environment (Taleb, 2012). Even if they do not give concrete examples of antifragile plans (rigid planning being by definition fragile), Blecic and Cecchini open the way for a new approach of intervention on geographic space: increase redundancies, leave some slack capacity in order to take advantage of unforeseeable opportunities, avoid optimization (which increases the fragility of any plan), take advantage of collective intelligence through participatory processes and bottom-up actions.

As far as risk management is concerned, uncertain events were traditionally described through probabilistic models. These probabilistic models were mobilized mainly to prevention purposes. In the presence of a possible risk, prevention means acting on the risk, even in a context of scientific uncertainty, by evaluating what is at stake and the magnitude of possible damage. One of the main critics to probabilistic approach of risk is that they are not conceived to deal with the unknown (Merad, 2010; Merad et al., 2016; Taleb, 2007). This new scientific uncertainty and uncertainty of non-intentional effects of actions produced two other management strategies. The first is the precautionary principle, 15th principle of the Rio Declaration. In the presence of a reasonable doubt, precaution means taking proportionate actions, even in a context of scientific uncertainty, by evaluating what is at stake and the magnitude of possible damage. The second is anticipative crisis management. The unpredictability of natural and social phenomena, the week capacity to foresee and anticipate, brought policies to favour crisis management more than risk 
management, by focusing actions on emergency measures, early-warning systems and procedures of general mobilization in the event of a crisis.

The very topic of crisis management reveals an interesting link with uncertainty in geographic data. Roche et al. (2013) highlight how VGI is becoming new precious resource in crisis management, in situations where authoritative uncertainty-assessed geographic data are of little help (catastrophic events have considerably changed the geographic reality, official data are outdated or unavailable, etc.). Globally, VGI helps reduce uncertainty in crisis management: it is a way through which collective intelligence is used to monitor a complex system in particularly critical conditions and foster collective action on it. At the same time, peer-review assessment of VGI could not be enough or fast enough in the context of crisis management. From this point of view, classical command and control management using only authoritative geographic information will have to accept much more uncertainty and adaptive intervention strategies in close link with bottom-up feeds of information.

In conclusion, the unpredictability of extreme events, the new role of citizens in project management (and in data production), the diversity of viewpoints associated with it, environmental concerns challenging the public interest of projects, all contribute to increase uncertainty in planning and risk management. In this respect, these conscious and coordinated interventions on geographic space could in the future be more demanding of uncertainty-based geographical analyses than they have traditionally been.

\section{Conclusions and perspectives}

Our review of questions of uncertainty in geographical research highlights a striking contrast. On the one hand, works on uncertain geographic data and their representation are particularly rich and varied, but are often focused on the most technical aspects of uncertainty treatment and underestimate impacts deriving from uncertainties in hypotheses and concepts. On the other hand, works on uncertain geographic concepts, synthetic knowledge and subjective perception of space are relatively rare and are seldom connected to operational issues of geographic data treatment. More holistic approaches emerge in planning and in complex systems analysis. Here, the practical and theoretical impossibility of predicting the future state of a geographic system brings researchers to more general conceptions of uncertainty, which go well beyond questions of data validity and error management. Traditional probabilistic modelling of uncertain events is also reconsidered, as the fitting of probabilistic laws seems less and less justified: traditional shallow uncertainties become thus medium or deep uncertainties (Walker et al., 2013). Advances of knowledge seem thus inevitably linked to the increasing awareness of uncertain knowledge and even of non-knowledge.

In his already mentioned foreword, Curran (2002) points to a certain pragmatism in uncertainty research in the geo-sciences: being more frequent, of smaller magnitude and more readily tractable in practice, measurement uncertainty has absorbed much of the research effort. Understanding uncertainty, linked to uncertainties in explanations, concept and model definitions, has a considerably greater magnitude, Curran admits, but fortunately enough, it also has a considerably lower frequency. From our perspective, this observation has far reaching implications. Very rare events, with disruptive outcomes, are precisely what Taleb (2007) defines as "black swans". Understanding uncertainty can thus easily become the black swan of the geographer's knowledge production process, undermining our research praxis and discrediting passage from academic research to decision support.

In this context, the scientific agenda for uncertainty-aware geographers seems to us the following. Instead of or (when possible) beyond reducing uncertainty, geographers 
should accept uncertainty as a necessary component of the research activity and results. Possible uncertainties in explanations, concept and model definitions should be given absolute priority, in order to avoid over-treatment of measurement uncertainties. Models of complex systems should not aim at replicating the simple sensitivity to parameter approach of classical models. Representation and decision support should reflect the state of our knowledge and take advantage of subjective perceptions within participative processes. Ideally, research agendas should be designed in more flexible ways to take advantage of a "positive uncertainty": considering the uncertainties associated to the different phases of the knowledge production process, from concept definition to data treatment and geosimulation, should produce more productive research heuristics. Conflicting, gradual, vague, imprecise, "soft" knowledge is the natural fuel of scientific work. Certain knowledge would thus be an extreme case, and even a less stimulating one in geographic research.

\section{Declaration of conflicting interests}

The author(s) declared no potential conflicts of interest with respect to the research, authorship, and/or publication of this article

\section{Funding}

The author(s) received no financial support for the research, authorship, and/or publication of this article.

\section{Note}

1. There is a large density of districts where the median or average voter is quite moderate, but voting behavior of the representative is extreme, and the legislature is far more sharply polarized than is the distribution of district medium.

\section{References}

Aerts J, Goodchild M and Heuvelink G (2003) Accounting for spatial uncertainty in optimization with spatial decision support systems. Transactions in GIS 7(2): 211-230.

Allen P (1997) Cities and Regions as Self-organizing Systems: Models of Complexity. Amsterdam: Gordon Breach Science Publishers.

Arnaud A and Davoine P-A (2009) Approchecartographique et géovisualisation pour la représentation de l'incertitude. SAGEO 2009, halshs-00667166, version 1, 7 February 2012.

Ban $\mathrm{H}$ and Ahlqvist $\mathrm{O}$ (2009) Representing and negotiating uncertain geospatial concepts - Where are the exurban areas? Computers, Environment and Urban Systems 33(4): 233-246.

Batty M (2013) The New Science of Cities. Boston: MIT Press.

Bendler J, Wagner S, Brandt T, et al. (2014) Taming uncertainty in big data. Business \& Information Systems Engineering 6: 279-288.

Benenson I and Torrens PM (2004) Geosimulation: Automata-Based Modeling of Urban Phenomena. London: John Wiley.

Bennett B (2001) What is a forest? On the vagueness of certain geographic concepts. Topoi 20: 189-201.

Berkes F and Folke C (eds) (1998) Linking Social and Ecological Systems: Management Practices and Social Mechanisms for Building Resilience. Cambridge, UK: Cambridge University Press.

Best S and Kellner D (1997) The Postmodern Turn. New York: Guilford Press.

Beven K and Freer J (2000) Equifinality, data assimilation, and uncertainty estimation in mechanistic modelling of complex environmental systems. Journal of Hydrology 249: 11-29. 
Blecic I and Cecchini A (2016) Verso Una Pianificazione Antifragile. Come Pensare Al futuro Senza Prevederlo. Milan: Franco Angeli.

Bobilo F and Straccia U (2011) Fuzzy ontology representation using OWL 2. International Journal of Approximate Reasoning 52: 1073-1094.

Boggs SW (1949) An atlas of ignorance: A needed stimulus to honest thinking and hard work. Proceedings of the American Philosophical Society 93: 253-258.

Burrough P and Frank A (eds) (1996) Geographic Objects with Indeterminate Boundaries. Gisdata Series. London: Taylor and Francis.

Brunet R (1980) La composition des modèlesdans l'analyse spatiale. L'Espacegéographique 4: 253-265.

Buttenfield BP and Weibel R (1988) Visualizing the quality of cartographic data. In: Third international geographic information systems symposium (GIS/LIS 88), San Antonio, Texas, USA, 30 November - 2 December 1988.

Caglioni M and Fusco G (2014) Formal Ontologies and Uncertainty in Geographical Knowledge. Journal of Land Use, Mobility and Environment (TeMA) 2014: 187-198.

Caloz R (2005) Réflexions sur les incertitudes et leur propagation enanalysespatiale. Revue Internationale de Géomatique 15: 303-319.

Cao C and Fusco G (2015) Representing uncertain futures: Social polarization in the metropolitan area of Marseille. Available at: https://public.tableau.com/profile/fusco\#!/vizhome/Representing UncertainFutures/Story1 (accessed 22 June 2017).

Capra F (1997) The Web of Life: A New Scientific Understanding of Living Systems. New York: Anchor Books.

Cedilnik A and Reinghans P (2000) Procedural annotation of uncertain information. In: Proceedings of Visualization '00, pp. 77-84. Washington: IEEE Computer Society Press.

Chalas Y and Soubeyran O (2010) Incertitude, environnement et aménagement: Quelle rupture? In: Chalas Y, Gilbert C and Vinck D. Comment les Acteurss'arrangent Avec L'incertitude. Paris: Editions des archives contemporaines, pp.135-157.

Chung JH and Lam TC (eds) (2010) China's Local Administration: Traditions and Changes in the Sub-national Hierarchy. New York: Routledge.

Comber A, Fisher P and Brown A (2007) Uncertainty, vagueness and indiscernibility: The impact of spatial scale in relation to the landscape elements and landscape questions. The International Archives of the Photogrammetry, Remote Sensing and Spatial Information Sciences 34: Part XXX.

Coombes M, Dixon J, Goddard J, et al. (1979) Urban systems in Britain: from theory to practice. Environment and Planning A 11: 565-574.

Cosgrove D (1998) Social Formation and Symbolic Landscape. Madison: University of Wisconsin Press.

Costa P, Laskey KB and Laskey KJ (2008) PR-OWL: A Bayesian Ontology Language for the Semantic Web (LNAI 5327). Germany: Springer-Verlag Berlin Heidelberg, pp. 88-107.

Couclelis H (2003) The certainty of uncertainty: GIS and the limits of geographic knowledge. Transactions in GIS 7: 165-175.

Couclelis H (2010) GIS and sketching. spatial@ucsb seminar. Available at: www.youtube.com/watch? $\mathrm{v}=$ VSUh1dMfdlM (accessed 22 June 2017).

Cuhls K (2003) From forecasting to foresight processes - New participative foresight activities in Germany. Journal of Forecasting 22: 93-111.

Curran P (2002) Forward with uncertainty. In: Foody G and Atkinson P (eds) Uncertainty in Remote Sensing and GIS. Chichester: John Wiley and Sons, pp.xi-xvi.

D'Acquino P and Bah A (2013a) Land policies for climate change adaptation in West Africa: A multilevel companion modelling approach. Simulation and Gaming 44: 391-408.

D'Acquino P and Bah A (2013b) A participatory modeling process to capture indigenous ways of adaptability to uncertainty: Outputs from an experiment in West African drylands. Ecology and Society 18: 16.

Daudé E (2005) Systèmes multi-agents pour la simulation engéographie: versuneGéographieArtificielle. In: Guermond Y (ed.) Modélisations en Géographie. Paris: Lavoisier, pp. 353-380.

Dauphiné A (2003) La Théorie de la Complexité Chez Les Géographes. Paris: Anthropos. 
Del Fatto V (2009) Visual Summaries of Geographic Databases by Chorems, PhD thesis, INSA Lyon, UniversitàdegliStudi di Salerno.

De Ruffray S (2007) L'imprécisionetl'incertitudeengéographie. L'apport de la logiquefloue aux problématiques de régionalisation,Mémoired'habilitation à diriger des recherches, Université de Paris VII, Volumes 1, 2 et 3, p. 588.

De Runz C (2008) Imperfection, temps etespace: Modélisation, analyse et visualisationdans un SIG archeologique. PhD Thesis, Université de Reims - Champagne Ardenne.

Didelon C, De Ruffray S, Boquet M, et al. (2011) Un monde d'interstices. Apport de la logique floue pour l'analyse des cartesinterprétatives. CFC 209: 71-82.

Di Méo G (1991) De l'espacesubjectif à l'espaceobjectif: L'itinéraire du labyrinthe. L'Espace Géographique 4: 359-373.

Di Méo G (2005) Les théories de la complexité font leurcheminengéographie. Annales de Géographie 114: 220.

Di Méo G (2012) Éléments de réflexion pour unegéographiesociale du genre: Le cas des femmes dans la ville. L'Information Géographique 76: 72-94.

Ding Z and Peng Y (2004) A probabilistic extension to ontology language OWL. In: Proceedings of the 37th Hawaii International Conference on System Sciences, Big Island (HI), 5-8 January 2004, doc 40111.1, pp. 1-10. Washington: IEEE Computer Society Press.

Dubois D, Fusco G, Prade H, et al. (2017) Uncertain logical gates in possibilistic networks: Theory and application to human geography. International Journal of Approximate Reasoning 82: $101-118$.

Dubois D and Prade H (1988) Possibility Theory: An Approach to Computerized Processing of Uncertainty. New York: Plenum Press.

Duckham M (2002) Uncertainty and geographic information: Computational and critical convergence. Research paper, Department of Computer Science, University of Keele, Staffordshire, UK.

Duckham M, Mason K, Stell J, et al. (2001) A formal approach to imperfection in geographic information. Computer, Environment and Urban Systems 25: 80-103.

Edwards L and Nelson E (2001) Visualizing data certainty: A case study using graduated circle maps. Cartographic Perspectives 38 (Winter): 19-36.

Ehlschlaeger C, Shortridge A and Goodchild M (1997) Visualizing spatial data uncertainty using animation. Computers \& Geosciences 23: 387-395.

Evans B (1997) Dynamic display of spatial data-reliability: Does it benefit the map user? Computers \& Geosciences 23: 409-422.

Federal Judicial Center (2011) Reference Manual on Scientific Evidence, 3rd ed. Washington: National Research Council of the National Academies.

Feynman R (1988) What do you Care What Other People Think. London: Harper Collins.

Fini C, Committeri G, Müller BCN, et al. (2015) How watching pinocchio movies changes our subjective experience of extrapersonal space. PLoS One 10: e0120306.

Fisher P (1994) Visualization of the reliability in classified remotely sensed images. Photogrammetric Engineering and Remote Sensing 60: 905-910.

Fisher P (2000) Sorites paradox and vague geographies. Fuzzy Sets and Systems 113: 7-18.

Fisher P (2005) Models of uncertainty in spatial data. In: Longley et al. (eds) Geographical Information Systems. Principles, Techniques, Management and Applications. Chichester: John Wiley and Sons, pp.191-205.

Fisher P, Comber A and Wadsworth R (2006) Approaches to uncertainty in spatial data. In: Devillers R and Jeansoulin R (eds) Fundamentals of Spatial Data Quality. London: ISTE, pp. 49-64.

Flanagin AJ and Metzger MJ (2008) The credibility of volunteered geographic information. GeoJournal 72: 137-148.

Foody G and Atkinson P (eds) (2002) Uncertainty in Remote Sensing and GIS. Chichester: Wiley.

Fusco G and Tettamanzi A (2017) Multiple Bayesian models for the sustainable city. The case of urban sprawl. ICCSA 2017 - 17th international conference on computational science and its applications, Trieste, 3-6 July 2017, Lecture Notes in Computer Science, Vol. 10407. Berlin: Springer (in press). 
Fusco G, et al. (2015) Faire science avec l'incertitude: Réflexions sur la production des connaissancesen Sciences Humaines et Sociales. Incertitude etc onnaissancesen SHS: Production, diffusion, transfert, June 2014, Nice, France. Available at: https://hal-univ-avignon.archives-ouvertes.fr/halshs01166287 (accessed 22 June 2017).

Gaines BR (1978) Fuzzy and Probability Uncertainty Logics. Information and Control 38: 154-169.

Halpern J (2005) Reasoning about Uncertainty. Cambridge, MA: MIT Press.

Harley B (1988) Maps, knowledge and power. In: Cosgrove D and Daniel S (eds) The Iconography of Landscape. Cambridge: Cambridge University Press, pp. 277-312.

Harrower M (2007) Representing uncertainty: Does it help people make better decisions? UCGIS Workshop, Geospatial Visualization and Knowledge Discovery Workshop, Citeseer, pp.1-4.

Harvey D (1969) Explanation in Geography. London: Edward Arnold Publishers.

He B, Fang T and Guo D (2004) Quality assessment and uncertainty handling in spatial data mining. In: Proceedings of the 12th international conference on geoinformatics, University of Gävle, Sweden, 7-9 June 2004. Available at: http://fromto.hig.se/ bjg/geoinformatics/files/p203.pdf (accessed 22 June 2017).

Heuvelink G (2002) Analysing uncertainty propagation in GIS: Why is it not that simple? In: Foody G and Atkinson P (eds) Uncertainty in Remote Sensing and GIS. Chichester: Wiley, pp.155-166.

Heuvelink G (2007) Error-aware GIS at work: Real world applications of the data uncertainty engine. The International Archives of the Photogrammetry, Remote Sensing and Spatial Information Sciences 34: Part XXX.

Hey J, Waples RS, Arnold ML, et al. (2003) Understanding and confronting species uncertainty in biology and conservation. Trends in Ecology and Evolution 18: 597-603.

Knight FH (1921) Risk, Uncertainty, and Profit. Boston, MA: Hart, Schaffner \& Marx, Houghton Mifflin Company.

Kolbe TH, Gröger G and Plümer L (2005) CityGML Interoperable Access to 3D City Models. In: Van Oosterom et al (eds) Geo-Information for Disaster Management. Berlin: Springer, pp. 883-899.

Kunz M, Regamey-Gret A and Hurni L (2011) Visualization of uncertainty in natural hazards assessment using an interactive cartographic information system. Natural Hazards 59: 1735-1751.

Lake RW (1993) Planning and applied geography: Positivism, ethics, and geographic information systems. Progress in Human Geography 17: 404-413.

Laskey K, Write E and Costa P (2010) Envisioning uncertainty in geospatial information. International Journal of Approximate Reasoning 51: 209-223.

Laurini R and Servigne S (2011) Leçons tirées d'une expérience de chorémisation automatique. SAGEO 2011, Paris, 3-8 July. Available at: http://liris.cnrs.fr/robert.laurini/text/LauriniServigne2.pdf.

Loinger G and Spohr C (2005) Prospective et planification territoriales, état des lieux et propositions. Travaux et recherches de prospective 24. Paris: DRAST/CPVS.

Loiseau Y, Boughanem M and Prade H (2006) Evaluation of term-based queries using possibilistic ontologies. Soft Computing in Web Information Retrieval, Studies in Fuzziness and Soft Computing 197: $135-160$.

Longley P, Goodchild M, Maguire D, et al. (2011) Geographic Information Systems and Science. London: Wiley.

Lorentz E (1969) Three approaches to atmospheric predictability. Bulletin of the American Meteorological Society 50: 345-349.

Lynch K (1960) The Image of the City. Boston: The MIT Press.

MacEachren A (1992) Visualizing uncertain information. Cartographic Perspectives 13: 10-19.

MacEachren A and Taylor D (1994) Visualization in Modern Cartography. Oxford: Pergamon.

Malpica J, Alonso M and Sanz M (2007) Dempster-Shafer Theory in geographic information systems: A survey. ESWA 32: 47-55.

Manson S (2001) Simplifying complexity: A review of complexity theory. Geoforum 32: 405-414.

McCarty N, Rodden J, Shor B, et al. (2014) Geography, Uncertainty, and Polarization. SSRN, vol. 2477157, 7 April 2014. 
Merad M (2010) Aide à La Décision et Expertise Engestion Des Risques. Paris: Editions Lavoisier.

Merad M, Dechy N, Dehouck L, et al. (2016) Risquesmajeurs, Incertitudes et Decisions - Approche pluri disciplinaire et Multisectorielle. Paris: MA Edition.

Monmonier M (1993) How to Lie with Maps. Chicago: University of Chicago Press.

Morin E (1990) Introduction à la Pensée Complexe. Paris: Seuil.

Morin E (1994) La Complexité Humaine. Paris: Champs Flammarion.

Murgante B, Las Casas G and Sansone A (2007) A spatial rough set for locating the periurban fringe. In: Batton-Hubert M, et al. (eds) SAGEO 2007, CD-ROM. Clermont-Ferrand: AgroParisTechENGREF.

Olteanu-Raimond AM, Mustière S and Ruas A (2009) Fusion des connaissances pour apparier des donnéesgéographiques. Revue Internationale de Géomatique 19: 321-349.

Ostermann FO and Spinsanti L (2011) A conceptual workflow for automatically assessing the quality of volunteered geographic information for crisis management. AGILE 2011, Utrecht, 18-21 April 2011. Available at: https://agile-online.org/conference_paper/cds/agile_2011/contents/pdf/shortpapers/ sp_122.pdf.

O'Sullivan D (2004) Complexity science and human geography. Transactions of the Institute of British Geographers 29: 282-295.

Pang A, Wittenbrink C and Lodha S (1997) Approaches to uncertainty visualization. The Visual Computer 13: 370-390.

Pellegrino M (2010) La dynamique des possibles. Incertitude etdurabilitédans les pratiques de transformation urbaine, PhD Thesis, Politecnico di Torino/Université Paris-Ouest.

Plewe B (2002) The nature of uncertainty in historical geographic information. Transactions in GIS 6: 431-456.

Prade H, Jeansoulin R, Papini O, et al. (eds) (2010) Methods for Handling Imperfect Spatial Information. Berlin: Springer.

Portugali J (2000) Self-organisation and the City. Berlin: Springer.

Pumain D and Reuillon R (2017) Urban Dynamics and Simulation Models. Berlin: Springer.

Quine W (1980 [1953]) From a Logical Point of View. Cambridge: Harvard University Press.

Reuillon R, Leclaire M and Passerat-Palmbach J (2015) Model exploration using OpenMOLE a workflow engine for large scale distributed design of experiments and parameter tuning. In: IEEE high performance computing and simulation conference 2015, Amsterdam, 20-24 June 2015, arXiv:1506.04182v1.

Ribeiro B, Albrecht RF, Dobnikar A, et al. (eds) (2005) Adaptive and Natural Computing Algorithms. Computer Science. Berlin: Springer.

Rocchini D, Hortal J, Lengyel S, et al. (2011) Accounting for uncertainty when mapping species distributions: The need for maps of ignorance. Progress in Physical Geography 35: 211-226.

Roche S, Propeck-Zimmerman E and Mericskay B (2013) GeoWeb and crisis management: Issues and perspectives of Volunteered Geographic Information. Geojournal 78: 21-40.

Rolland-May C (1984) Les EspacesGéographiques flous. Thèsed'Etaten Sciences Humaines, Université de Metz, France.

Rowntree B (1997) Les cartesmentales, outilgéographique pour la connaissanceurbaine. Le casd'Angers (Maine-et-Loire). Norois 176: 585-604.

Scherrer F and Vanier M (dir.) (2013) Villes, Territoires, Réversibilités, Hermann, collection Colloques de Cerisy. France: Hermann Editeur.

Scrivener S, Ball L and Tseng W (2000) Uncertainty and sketching behaviour. Design Studies 21: 465-481.

Shafer G (1976) A Mathematical Theory of Evidence. Princeton, NJ: Princeton University Press.

Shu H, Spaccapietra S, Parent C, et al. (2003) Uncertainty of geographic information and its support in MADS. In: Proceedings of ISSDQ, Hong Kong, 19-20 March 2003, pp. 1-13.

Smith N (1979) Geography, science and post-positivist modes of explanation. Progress in Human Geography 3: 356-383.

Taleb NN (2007) The Black Swan: The Impact of the Highly Improbable. New York: Random House. Taleb NN (2012) Antifragile. Things That Gain From Disorder. New York: Random House. 
Thill J-C and Sui DZ (1993) Mental maps and fuzziness in space preferences. The Professional Geographer 45: 264-276.

Tobler WR (1979) Cellular geography. Philosophy in Geography 20: 379-386.

Tuan Y-F (1977) Space and Place: The Perspective of Experience. Minneapolis: University of Minnesota Press.

Uusitalo L, Lehikoinen A, Helle I, et al. (2015) An overview of methods to evaluate uncertainty of deterministic models in decision support. Environmental Modelling \& Software 63: 24-31.

Varenne F (2015) La sous-détermination des modèlesexplicatifs par les loisempiriques: Un problèmerécurrentmaisfécondengéographie de modélisation. In: Blanckaert $\mathrm{C}$ et al. (eds) Modèles et Modélisations, en Sciences Du Langage, de L'homme et de La Société. Perspectives Historiques et Épistémologiques. Paris: L’Harmattan.

Vazirgiannis M, Halkidi M and Gunopulos D (2003) Uncertainty Handling and Quality Assessment in Data Mining. London - Berlin - Heidelberg: Springer.

Visser H, Petersen AC, Beusen AHW, et al. (2006) Guidance for uncertainty assessment and communication. Report 550032001/2006, The Hague: Netherlands Environmental Assessment Agency.

Von Bertalanffy L (1968) General System Theory. New York: George Braziller.

Walker W, et al. (2003) Defining uncertainty: A conceptual basis for uncertainty management in model-based decision support. Integrated Assessment 4: 5-17.

Walker W, Lempert R and Kwakkel J (2013) Deep uncertainty. In: Glass S and Fu M (eds) Encyclopedia of Operations Research and Management Science. Berlin: Springer, pp. 395-402.

Weaver W (1948) Science and complexity. American Scientist 36: 536-544.

Weichhart G (2013) The Learning Environment as a Chaotic and Complex Adaptive System: ELearning Support for Thrivability. Systems 1: 36-53.

Zadeh L (1978) Fuzzy sets as the basis for a theory of possibility. Fuzzy Sets and Systems 1: 3-28.

Zbilut JP and Giuliani A (2008) Biological uncertainty. Theory in Biosciences 127: 223-227.

Zhang J and Goodchild M (2002) Uncertainty in Geographical Information. London: Taylor \& Francis. 